\title{
Ambient particulate air pollution and acute lower respiratory infections: a systematic review and implications for estimating the global burden of disease
}

\author{
Sumi Mehta • Hwashin Shin • Rick Burnett • \\ Tiffany North $\cdot$ Aaron J. Cohen
}

Received: 7 February 2011 /Accepted: 5 May 2011 /Published online: 21 May 2011

(C) The Author(s) 2011. This article is published with open access at Springerlink.com

\begin{abstract}
Acute lower respiratory infections (ALRI) account for nearly one fifth of mortality in young children worldwide and have been associated with exposures to indoor and outdoor sources of combustion-derived air pollution. A systematic review was conducted to identify relevant articles on air pollution and ALRI in children. Using a Bayesian approach to meta-analysis, a summary estimate of $1.12(1.03$, 1.30) increased risk in ALRI occurrence per $10 \mu \mathrm{g} / \mathrm{m}^{3}$ increase in annual average $\mathrm{PM}_{2.5}$ concentration was derived from the longer-term (subchronic and chronic) effects studies. This analysis strengthens the evidence for a causal relationship between exposure to $\mathrm{PM}_{2.5}$ and the occurrence of ALRI and provides a basis for estimating the global attributable burden of mortality due to ALRI that is not influenced by the wide variation in regional case fatality rates. Most studies, however, have been conducted in settings with relatively low levels of $\mathrm{PM}_{2.5}$. Extrapolating their results to other, more polluted, regions will require a model that is informed by evidence from studies of the effects on ALRI of exposure to $\mathrm{PM}_{2.5}$ from other combustion sources, such as secondhand smoke and household solid fuel use.
\end{abstract}

S. Mehta $(\bowtie) \cdot$ T. North $\cdot$ A. J. Cohen

Health Effects Institute,

101 Federal Street, Suite 500,

Boston, MA 02110, USA

e-mail: sumi.mehta@gmail.com

H. Shin · R. Burnett

Population Studies Division, Environmental Health Science

and Research Bureau, Health Canada,

Ottawa, ON, Canada

H. Shin • R. Burnett

Institute of Population Health, University of Ottawa,

Ottawa, ON, Canada
Keywords Global health $\cdot$ Air pollution $\cdot$ ALRI $\cdot$ Health impact assessment
Abbreviation
ALRI Acute lower respiratory infection
$\mathrm{NO}_{2} \quad$ Nitrogen dioxide
$\mathrm{O}_{3} \quad$ Ozone
$\mathrm{PM}_{10} \quad$ Particulate matter $\leq 10 \mu \mathrm{m}$ in aerodynamic diameter
$\mathrm{PM}_{2.5}$ Particulate matter $\leq 2.5 \mu \mathrm{m}$ in aerodynamic diameter
SHS Secondhand smoke
$\mathrm{SO}_{2} \quad$ Sulfur dioxide
WHO World Health Organization

\section{Introduction}

Acute lower respiratory infections (ALRI), including pneumonia and bronchiolitis of bacterial and viral origin, are the largest single cause of mortality among young children worldwide and thus account for a significant global burden of disease worldwide (Williams et al. 2002). Cases are nearly always diagnosed clinically, based on severe respiratory symptoms, where ALRI is characterized by acute-onset cough or difficulty in breathing with fast breathing for age and severe ALRI defined as acute cough or difficulty in breathing with indrawing of the lower chest wall necessitating hospital admission (Nair et al. 2010). According to recent estimates, these infections cause nearly one fifth of mortality in children under the age of 5 years, with $90 \%$ of ALRI deaths being directly attributable to pneumonia. A substantial fraction of the burden is experienced by populations in Asia and Africa, with 134 and 131 million cases of lower respiratory infections occurring each year in Asia and Africa, respec- 
tively, out of an overall global annual total of 429.2 million cases for all ages.

Outdoor air pollution has been associated with increased ALRI mortality and with increased symptoms, admissions to hospitals, and ER visits. The bulk of the evidence on mortality and hospital admissions from pneumonia have comes from studies of short-term exposures to lower concentrations of outdoor air pollution in developed countries (Braga et al. 2001; Zanobetti et al. 2000). A small number of studies have also been conducted in developing countries (Romieu et al. 2002). Toxicologic evidence suggests that exposure to particulate air pollution can cause pulmonary inflammation and affect host defenses against infection (Samet et al. 2006). The World Health Organization (WHO) estimated that exposure urban outdoor $\mathrm{PM}_{2.5}$ caused approximately 25,600 deaths and over 862,000 lost years of healthy life due to ALRI in 2000 (Cohen et al. 2004).

This paper describes a systematic review and metaanalysis conducted to quantify the risk of ALRI associated with ambient concentrations of $\mathrm{PM}_{2.5}$. This estimate will be used along with evidence from other combustion sources, including household solid fuel use and secondhand smoke (SHS), to derive $\mathrm{PM}_{2.5}$ concentration-response (C-R) function for incidence of child ALRI in the next update of the burden of disease from outdoor air pollution. ${ }^{1}$

\section{Approach}

Systematic review of ALRI literature

A systematic review of the literature on air pollution and ALRI was conducted to identify articles on air pollution and ALRI in children. A PubMed search was conducted on September 24, 2008 using the following search criteria:

PubMed search string: (ALRI OR ARI OR pneumonia OR respiratory illness OR respiratory infection OR respiratory disease OR fast breathing OR chest indrawing OR fast breath* OR rapid breath* OR raised respiratory rate OR RSVOR bronchiolitis OR streptococcus pneumoniae OR pneumonococcus OR haemo-

\footnotetext{
${ }^{1}$ Global Burden of Disease (GBD) 2010 is the first major effort since the original GBD 1990 study to carry out a complete systematic assessment of the data on all diseases and injuries and produce comprehensive and comparable estimates of the burden of diseases, injuries, and risk factors for two time periods, 1990 and 2005. GBD is a multi-center collaboration funded by the Bill and Melinda Gates Foundation and led by the Institute for Health Metrics and Evaluation at the University of Washington, with key collaborating institutions including WHO, Harvard University, Johns Hopkins University, and the University of Queensland. For more information, visit www. globalburden.org.
}

philus influenza OR h. influenza OR respiratory tract diseases) AND (air pollution OR air pollutants OR air quality) AND (child OR preschool OR infant OR children*)

Search results were screened by title, then by abstract, to eliminate irrelevant articles. Potentially relevant articles were then reviewed to eliminate non-original studies (reviews, etc.), studies without children's health endpoints, and studies reporting only respiratory symptoms prevalence, asthma, and allergy (non-relevant outcomes).

Approach to meta-analysis

We estimated a distribution of the true relative risk for ALRI occurrence associated with ambient $\mathrm{PM}_{2.5}$ based on longer-term (subchronic and chronic) effects studies using a Bayesian (Markov Chain Monte Carlo) approach. Because we believe that in the absence of bias the relative risk must be either greater than or equal to 1.0 (i.e., $\mathrm{PM}_{2.5}$ cannot reduce the risk of ALRI), our analyses assume that the study-specific results are derived from a gamma distribution specified by a shape and scale parameters for the summary relative risk. The gamma distribution also can characterize variation in risk among studies in a nonsymmetric manner, a pattern often observed.

To estimate the risk coefficient, we ran three sequences (chains) of the Gibbs sampler for 11,000 iterations using different initial values and removed the first 1,000 samples. We assessed convergence through the use of trace plots. All estimates were obtained by WinBUGS (version 1.4.3, http://www.mrc-bsu.cam.ac.uk/bugs/). A detailed description of the approach taken is provided in "Appendix".

Where studies presented risk estimates for multiple age groups, we focused on the results for children $<2$ years of age, since this is the age group most susceptible to ALRI. As a sensitivity analysis, we also compared the results of our approach with results obtained using more 'conventional' fixed and random effects approaches.

\section{Results}

Systematic review of ALRI literature

- The initial search identified 5,758 publications. Screening by title and eliminating non-human studies eliminated a bulk of the initial publications, resulting in 376 articles. Remaining abstracts were screened to eliminate non-original studies (reviews, etc.), studies without children's health endpoints, and studies reporting only respiratory symptoms prevalence, 
asthma, allergy (non-relevant outcomes). This eliminated another 300 publications, resulting in 74 potentially relevant publications. A summary of the studies by design and outcome category are given in Table 1.

- We are aware that this search strategy did not adequately capture the evidence on respiratory mortality. For example, while we are aware of a handful of studies which have focused on respiratory mortality (Ritz et al. 2006; Woodruff et al. 1997, 2006, 2008), all four cohort studies identified focused on morbidity outcomes.

- The vast majority of studies have been conducted in Europe and North America (42 studies), and a substantial number of studies ( 24 studies) have been conducted in Latin American. Asia (four studies), the Middle East (three studies), the South Pacific/Oceania region, and Africa (zero studies) are seriously underrepresented in the literature.

\section{Evidence from short-term studies}

Time series studies We identified five time series studies investigating the association between ambient exposure to particular matter and ALRI in young children through a systematic review of literature. Three of the studies were conducted in Brazil (Braga et al. 2001; Conceicao et al. 2001; Gouveia and Fletcher 2000; Saldiva et al. 1994), and the other two studies were carried out in Mexico (Hernandez-Cadena et al. 2007) and Chile (Ostro et al. 1999). Six of these time series studies identified a relationship between ALRI morbidity or mortality and increases in $\mathrm{PM}_{10}$ exposure, with relative risk estimates ranging from 1.00 and 1.09 for every $10-\mu \mathrm{g} / \mathrm{m}^{3}$ increase in $\mathrm{PM}_{10}$ exposure.

Table 1 Summary of epidemiologic studies of air pollution and ALRI identified as of September 2008

\begin{tabular}{lccc}
\hline Study design & Morbidity & Mortality & Total studies \\
\hline Cohort & 4 & 0 & 4 \\
Time series & 31 & 5 & 36 \\
Case control & 3 & 2 & 5 \\
Panel & 3 & 0 & 3 \\
Ecologic & 6 & 1 & 7 \\
Case crossover & 6 & 1 & 7 \\
Cross sectional & 9 & 3 & 11 \\
Intervention & 1 & 0 & 1 \\
Total & 62 & 12 & 73 \\
\hline
\end{tabular}

Deb (1998) looked about both morbidity and mortality for ALRI in relation to air pollution which accounts for the difference in totals between morbidity and mortality combined and the total number of studies in the last column
Increased risks were observed in both of the studies conducted in Brazil, with stronger effects observed among the younger age groups. Braga et al. (2001) observed a $3 \%$ increase in respiratory admissions (relative risk (RR) $1.026[1.022,1.030]$ ) for children under 3 and a $1 \%$ increase (RR 1.009 [1.001, 1.018]) in respiratory admissions among children aged 3-5. Ostro et al. (1999) found a similar risk among Chilean children under 2 years of age (RR 1.012 [1.008, 1.016]). Gouveia and Fletcher (2000) identified a $1 \%$ higher risk of infant pneumonia (RR 1.009[1.001, 1.017]) and a similar risk among the under-five age group as a whole (RR 1.005 [0.998, 1.012]). Hernandez-Cadena et al. (2007) also reported an increased risk of similar magnitude in Mexican children and infants below age 6 associated with $\mathrm{PM}_{10}$ exposure (RR 1.007 [0.987, 1.027]).

Case-crossover studies In addition to the studies identified through our systematic search, we have also summarized results from a recently published study conducted in Ho Chi Minh City, Vietnam (Collaborative Working Group (CWG) on Air Pollution Poverty and Health in HCMC 2011). The study was not quantitatively included in any summary estimate, so its inclusion should not bias any results presented here. We believe it is important to include a summary of its results because it fills a major gap in the available evidence from Asia, with some of the highest concentrations $\left(>70 \mu \mathrm{g} / \mathrm{m}^{3}\right.$ annual average $\left.\mathrm{PM}_{10}\right)$ measured among these studies.

Studies conducted in the USA, France, Australia, Vietnam, and New Zealand have found a positive association between PM exposure and ALRI admissions among children below 5 years of age (Barnett et al. 2005; Collaborative Working Group (CWG) on Air Pollution Poverty and Health in HCMC 2011; Karr et al. 2006; Segala et al. 2008). Studies that have found the strongest PM effects generally focus specifically on bronchiolitis (Karr et al. 2006; Segala et al. 2008), while most of the studies which have used a more broadly grouped disease classification have found similarly inconclusive results for $\mathrm{PM}_{10}$ (Barnett et al. 2005; Gouveia and Fletcher 2000; Hernandez-Cadena et al. 2007).

Although studies have looked for potential effect modification by season, the definition of season used has varied from study to study, with the strongest effects generally observed in winter (Barnett et al. 2005; Gouveia and Fletcher 2000; Hernandez-Cadena et al. 2007; Karr et al. 2006). Regions with a predominantly tropical climate would have little variation in temperature, but distinct seasonal patterns with regard to rainfall that are correlated with distributions of respiratory infections. In the Giang study, for example, exposure to air pollutants was generally positively associated with ALRI during the dry season 
(November-April) and inversely associated with pollution in the rainy season (May-October), with limited evidence suggesting that seasonal differences in the prevalence of viral causes of ALRI could be driving the observed differences in effects by season (Collaborative Working Group (CWG) on Air Pollution Poverty and Health in HCMC 2011). Table 2 and Fig. 1 summarize the short-term studies, including information on the average concentrations reported in each study location.

\section{Evidence from longer-term studies}

Six longer-term studies were identified. All explore associations with some form of particulate pollution and respiratory health, but not all of them are focused directly on children $0-5$ and ALRI (see Table 3 for a summary of these studies).

Mülhing 1984 Muhling et al. (1984) conducted a retrospective study on the association between air pollution and children's (aged 0-4) hospitalizations for croup and obstructive bronchitis (Muhling et al. 1984). The study compared residential areas with different $\mathrm{SO}_{2}$ and dust concentration. Despite several efforts, we were unable to obtain a full text version of the study.

Brauer 2002 The cohort in Brauer et al. (2002) consisted of 3701 infants and children ages 2 years and younger from the Prevention and Incidence of Asthma and Mite Allergy study, a prospective birth cohort recruited between 1996 and 1997 from rural and urban communities in northern, western, and central parts of the Netherlands (Brauer et al. 2002). Using logistic regression analysis, Brauer et al. compared physician-diagnosed bronchitis from parental questions to measurements of $\mathrm{PM}_{2.5}$ at 40 individual monitoring sites combined with GIS data on traffic variability. The average concentration of $\mathrm{PM}_{2.5}$ was $16.9 \mu \mathrm{g} / \mathrm{m}^{3}$ during the exposure period based on measurements conducted for four 2-week periods dispersed throughout each year. Thus, the study provides evidence at the lower end of the exposure-response curve, with min and max $\mathrm{PM}_{2.5}$ concentrations of 13.5 and $25.2 \mu \mathrm{g} / \mathrm{m}^{3}$, respectively. Note that these are within the reference levels used in Hertz-Picciotto et al. (2007) (described below). After adjustment for season, temperature, and other covariates (parental education, environmental tobacco smoke (ETS), breastfeeding, presence of allergens, region of residence, siblings, ethnicity, indoor combustion sources, age of mother at time of birth), the investigators found positive but statistically insignificant associations for bronchitis and air pollution in children below 2 years of age.
Hertz-Picciotto 2007 The cohort in Hertz-Picciotto et al. (2007) consisted of a subset of 452 children age $0-4.5$ years from the Pregnancy Outcome Study, a prospective birth cohort recruited between 1994 and 1999 from the Czech districts of Teplice or Prachatice (Hertz-Picciotto et al. 2007). Using logistic regression analysis, Hertz-Picciotto et al. compared physician-diagnosed bronchitis from pediatric medical records of physician visits and hospitalizations to data collected from $\mathrm{PM}_{2.5}$ monitoring data. The average concentration of $\mathrm{PM}_{2.5}$ was $22.3 \mu \mathrm{g} / \mathrm{m}^{3}$ during the exposure period based on measurements performed daily in November-March, every third day in April-June, and September-October, and every sixth day in July-August of each year. After adjustment for season, temperature, and other covariates (age of child, current breastfeeding status, ETS, year of birth and sex), the investigators found positive associations for bronchitis and air pollution in children below 4.5 years of age with stronger associations for longer pollutant-averaging periods; $1.30(1.08,1.58)$ increased risk of bronchiolitis was observed for every $25 \mu \mathrm{g} / \mathrm{m}^{3}$ increase in $\mathrm{PM}_{2.5}$, with 30-day average concentrations of $\mathrm{PM}_{2.5}$ of $22.3 \mu \mathrm{g} / \mathrm{m}^{3}$ observed. The highest associations were observed among children 2-4.5 years of age at concentrations greater than $50 \mu \mathrm{g} / \mathrm{m}^{3}$.

Pouliou 2008 The recent re-analysis of the Hamilton children's cohort study using land-use regression to estimate exposures (Pouliou et al. 2008) revealed stronger associations between children's respiratory health and air pollution exposure than were found in the previous analyses. Increased exposure to TSP was associated with respiratory symptoms as well as pulmonary function. While this study does not provide $\mathrm{C}-\mathrm{R}$ function estimates, it does provide additional biological plausibility (via pulmonary function evidence) for the association between long-term exposures to particulate pollution and children's respiratory health, albeit for an older age group.

Karr 2007 The 18,595 cases and 169,572 controls in Karr et al. (2007) were identified from a California Office of Statewide Health Planning and Development data set that linked the birth data for South Coast Air Basin between 1995 and 2000 to hospital records for the first year of life (Karr et al. 2007). Cases were defined as all infants $(<1$ year of age) who had a hospital discharge of bronchiolitis in the first year of life. Using conditional logistic regression analysis, Karr et al. compared hospitalization discharge records of bronchiolitis to zip code linked $\mathrm{PM}_{2.5}$ data from 17 monitoring stations. The average concentration of $\mathrm{PM}_{2.5}$ was $25.0 \mu \mathrm{g} / \mathrm{m}^{3}$ during the exposure period based on daily average measurements performed every third day throughout each year. "Subchronic" exposures were defined as the average daily pollutant levels for the 30 days prior to 


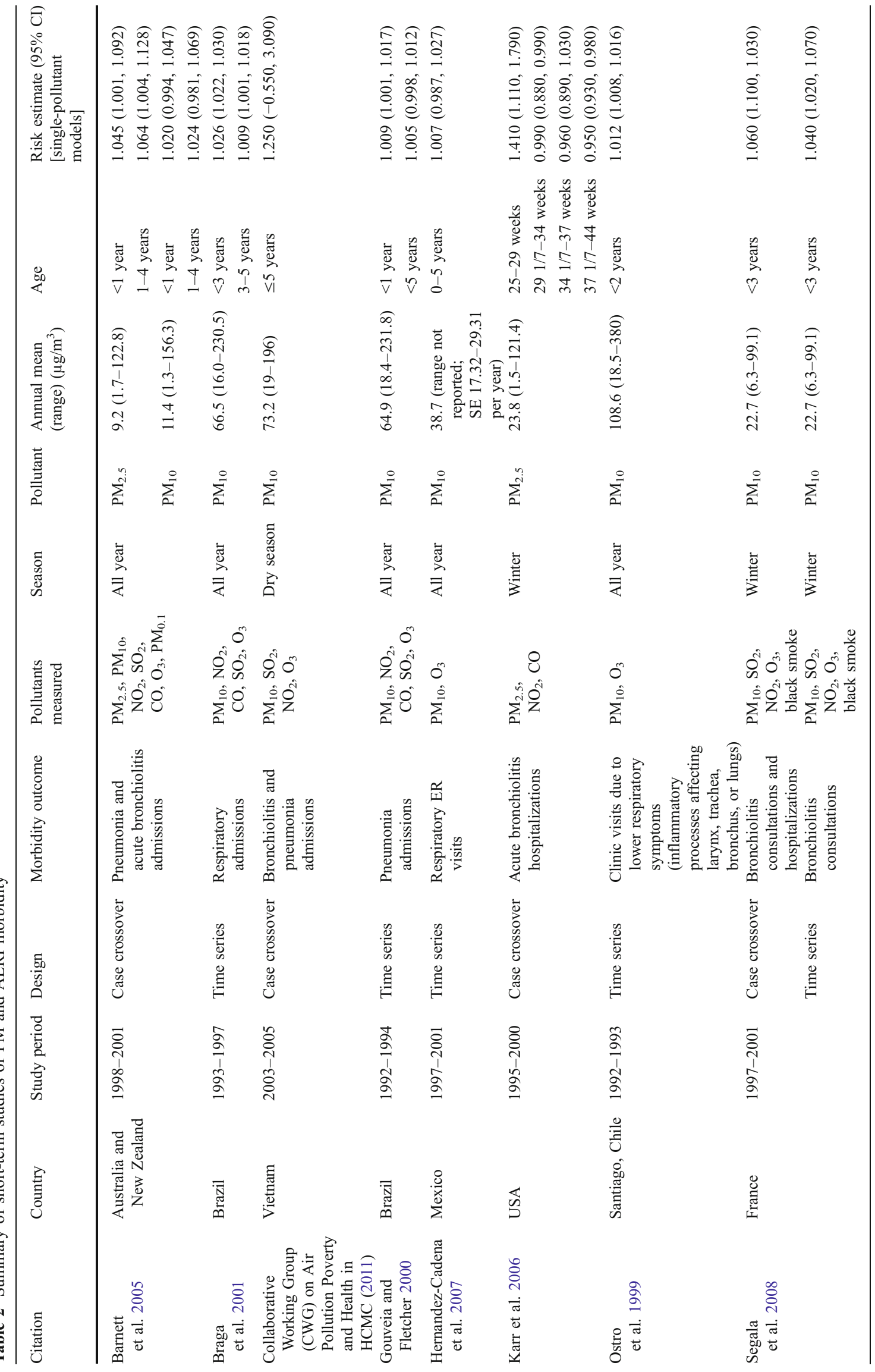




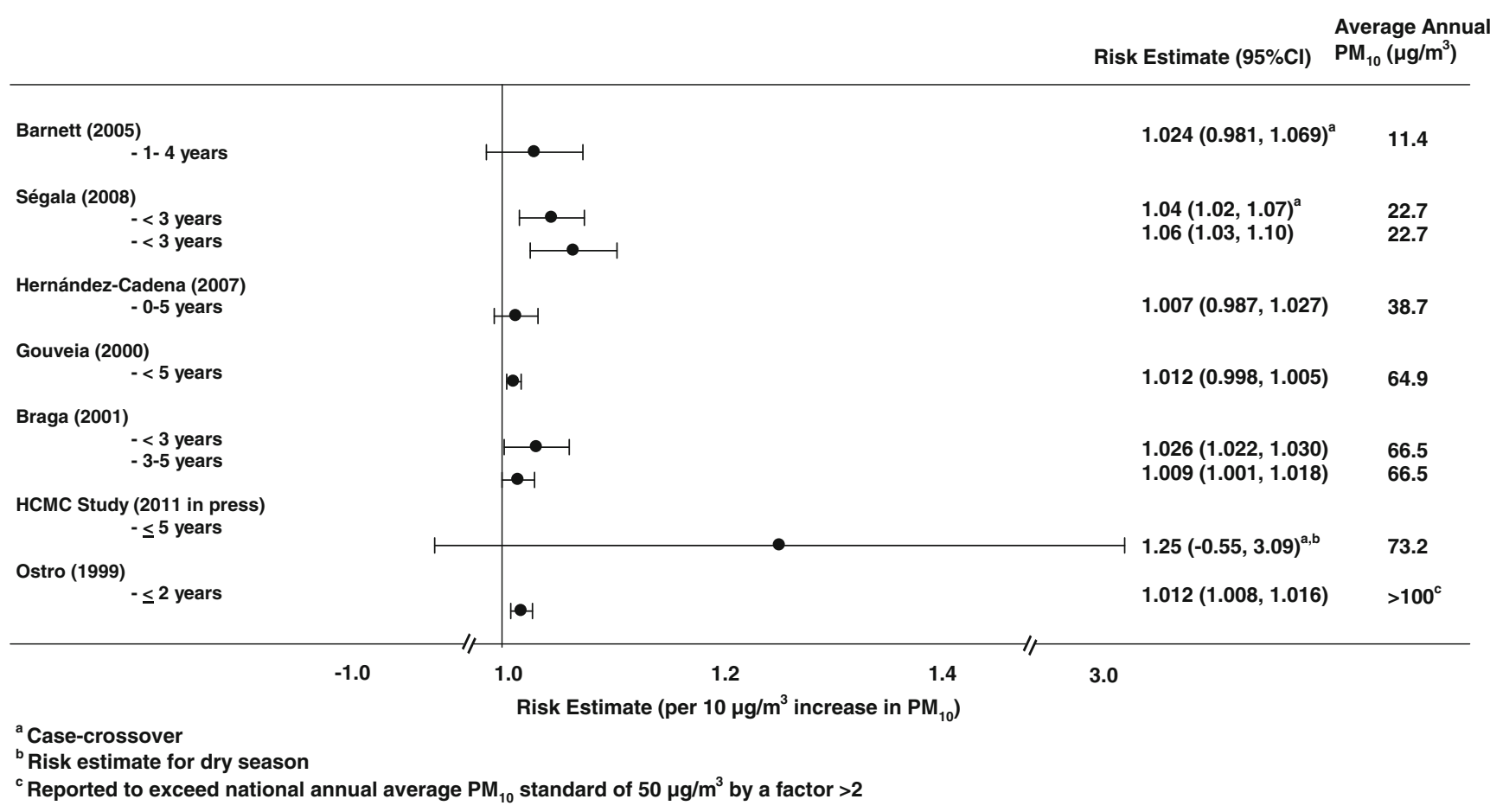

Fig. 1 Risk estimates from short-term studies of $\mathrm{PM}_{10}$ and ALRI morbidity in children under 5 years of age, ordered by average annual PM 10 concentration

hospitalization, while "chronic exposure" was defined as the mean monthly levels from birth to date of hospitalization. After matching cases and controls on age, gestational age, and season of birth and adjusting for season, temperature, and other covariates (sex, parity, chronic lung disease, cardiac or pulmonary anomalies, insurance category, ethnicity, and maternal education), the investigators found strong associations for bronchiolitis and longer-term exposures to air pollution in infants below 1 years of age, with an association between $\mathrm{PM}_{2.5}$ exposures and increased risk of bronchiolitis hospitalization (per $10 \mu \mathrm{g} / \mathrm{m}^{3}$ increase, adjusted odds ratio $(\mathrm{OR})=1.09$ [1.04-1.14]).

Karr 2009 The 2604 cases and 23,354 controls in Karr et al. (2009) were identified from the Washington State Birth Events Registry database that linked the birth data for Puget Sound between 1997 and 2003 to hospital records for the first year of life (Karr et al. 2009). Cases were defined as all infants who had a hospitalization discharge of bronchiolitis in the first year of life. Using conditional logistic regression analysis, Karr et al. compared hospitalization discharge records of bronchiolitis to data from $\mathrm{PM}_{2.5}$ ambient monitors within $20 \mathrm{~km}$ of the subject's birth residence. The average concentration of $\mathrm{PM}_{2.5}$ was $12.1 \mu \mathrm{g} / \mathrm{m}^{3}$ during the exposure period based on daily average measurements performed every third day throughout each year.
After matching cases and controls on date of birth, gestational age, and length of birth hospitalization and adjusting for season, temperature, and other covariates (residential proximity to traffic, maternal smoking during pregnancy, race/ethnicity, maternal education, insurance category, sex, parity and prenatal care), the investigators found some positive and some inverse but statistically insignificant associations for bronchiolitis and subchronic (30 days prior to hospitalization), chronic (60 days prior to hospitalization), and lifetime (mean daily levels from birth to date of hospitalization) exposures to air pollution in infants below 1 years of age. $\mathrm{PM}_{2.5}$ exposures were associated with increased risk of bronchiolitis hospitalization, with stronger effects observed with longer averaging times; lifetime exposures were associated with a $4 \%$ increase in hospitalizations (adjusted $\mathrm{OR}=1.04[0.83-1.29]$ per $10 \mu \mathrm{g} / \mathrm{m}^{3}$ increase) at average exposure concentrations of 11.6$12.6 \mu \mathrm{g} / \mathrm{m}^{3}$. Over $91 \%$ of cases were diagnosed during the winter months (from November to April), and similar risks were observed for "all bronchiolitis" and "RSV bronchiolitis."

\section{Meta-analysis}

The per unit risk and standard errors were extracted from the four studies with relevant and available data. Under the Bayesian approach, the risk of ALRI per $10 \mu \mathrm{g} / \mathrm{m}^{3}$ of $\mathrm{PM}_{2.5}$ 
Table 3 Summary of longer-term studies of PM and ALRI

\begin{tabular}{|c|c|c|c|c|c|}
\hline Citation & Location & Age group & Outcome & Pollutants & Results \\
\hline Brauer et al. 2002 & the Netherlands & 1 to 2 years & $\begin{array}{l}\text { Physician-diagnosed } \\
\text { ALRI }\end{array}$ & $\mathrm{PM}_{2.5}, \mathrm{NO}_{2}$, soot & $\begin{array}{l}\text { The adjusted ORs for interquartile increases in } \\
\mathrm{PM}_{2.5} \text { (equivalent to } 3.2 \mu \mathrm{g} / \mathrm{m}^{3} \text { ) were } 1.04 \\
{[0.85-1.26] \text { for doctor-diagnosed bronchitis }} \\
\text { and } 1.12[1.00-1.27] \text { for doctor-diagnosed } \\
\text { flu/serious colds. For } \mathrm{NO}_{2}\left(10.3 \mu \mathrm{g} / \mathrm{m}^{3}\right), \\
\text { the ORs were } 0.99[0.84-1.17] \text { for bronchitis } \\
\text { and } 1.11[1.00-1.23] \text { for flu/serious colds. } \\
\text { For soot }\left(0.54 \times 10^{-5} / \mathrm{m}\right) \text {, the ORs were } 0.99 \\
{[0.84-1.17] \text { for bronchitis and } 1.09[0.98-1.21]} \\
\text { for flu/serious colds }\end{array}$ \\
\hline $\begin{array}{l}\text { Hertz-Picciotto } \\
\text { et al. } 2007\end{array}$ & Czech Republic & $\begin{array}{l}1 \text { month to } \\
4.5 \text { years }\end{array}$ & Hospital admission & $\mathrm{PM}_{2.5}$, PAHs & $\begin{array}{l}\text { Below } 2 \text { years of age, the adjusted ORs for } \\
\text { bronchitis were } 1.29[1.07-1.54] \text { for IQR } \\
\text { increases in ambient PAHs (equivalent to } \\
100 \mathrm{ng} / \mathrm{m}^{3} \text { ) and } 1.30[1.08-1.58] \text { for increases } \\
\text { in } \mathrm{PM}_{2.5}\left(\text { equivalent to } 25 \mu \mathrm{g} / \mathrm{m}^{3} \text { ). For }\right. \\
\text { bronchitis in children } 2 \text { to } 4.5 \text { years of age, the } \\
\text { ORs for exposure to the same increments of } \\
\text { PAHs and } \mathrm{PM}_{2.5} \text { were } 1.56[1.22-2.00] \text { and } 1.23 \\
{[0.94-1.62], \text { respectively }}\end{array}$ \\
\hline Karr et al. 2007 & USA & 0 to 1 year & Hospital admission & $\mathrm{PM}_{2.5}, \mathrm{NO}_{2}, \mathrm{CO}, \mathrm{O}_{3}$ & $\begin{array}{l}\mathrm{PM}_{2.5} \text { exposures were associated with increased } \\
\text { risk of bronchiolitis hospitalization } \\
\text { (per } 10 \mu \mathrm{g} / \mathrm{m}^{3} \text { increase, adjusted } \mathrm{OR}=1.09 \\
[1.04-1.14]) . \text { Ozone was associated with } \\
\text { reduced risk in the single-pollutant model, } \\
\text { but this relation did not persist in } \\
\text { multipollutant models including } \mathrm{PM}_{2.5}\end{array}$ \\
\hline Karr et al. 2009 & USA & 0 to 1 year & Hospital admission & $\mathrm{PM}_{2.5}, \mathrm{NO}_{2}$ & $\begin{array}{l}\mathrm{PM}_{2.5} \text { exposures ( } 7 \text { day, } 30 \text { day, } 60 \text { day, lifetime) } \\
\text { were associated with increased risk of } \\
\text { bronchiolitis hospitalization, with the strongest } \\
\text { effects associated with lifetime exposures } \\
\text { (per } 10 \mu \mathrm{g} / \mathrm{m}^{3} \text { increase, adjusted OR }=1.04 \\
{[0.83-1.29] \text { ) at average exposure concentrations }} \\
\text { of } 11.6-12.6 \mu \mathrm{g} / \mathrm{m}^{3} \text {. Similar risks associated } \\
\text { with all bronchiolitis and RSV bronchiolitis } \\
\text { observed }\end{array}$ \\
\hline Muhling et al. 1984 & Germany & 0 to 4 years & Hospital admission & $\mathrm{SO}_{2}$, dust & $\begin{array}{l}\text { The results show a definitive connection between } \\
\text { a high rate of hospital admissions for respiratory } \\
\text { symptoms and high levels of } \mathrm{SO}_{2} \text { and dust. } \\
\text { This association was particularly marked in } \\
\text { areas with high levels of both pollutants }\end{array}$ \\
\hline Pouliou et al. 2008 & Canada & 9 to 12 years & Hospital admission & $\mathrm{TSP}, \mathrm{SO}_{2}$ & $\begin{array}{l}\text { The association between the occurrence of } \\
\text { the outcome "cold goes to chest" in children } \\
\text { and total suspended particulates was weak } \\
\text { (OR } 1.01[1.005,1.019]) \text {. But children were } \\
\text { slightly more likely to experience the symptom } \\
\text { if TSP pollution increased by } 1 \mu \mathrm{g} / \mathrm{m}^{3}\end{array}$ \\
\hline
\end{tabular}

was estimated to be $0.117(0.030,0.260)$. This translates into a relative risk of $1.12(1.03,1.30)$ per $10 \mu \mathrm{g} / \mathrm{m}^{3} \mathrm{PM}_{2.5}$. The fixed and random effects approaches gave nearly identical results which were smaller than the results of the Bayesian approach. Only the Bayesian approach, however, provided non-zero between-cohort variation (see Table 4 and Figs. 2 and 3).

\section{Discussion}

Based on the results of this review, each $10-\mu \mathrm{g} / \mathrm{m}^{3}$ increase in long-term ambient $\mathrm{PM}_{2.5}$ concentrations is associated with around a $12 \%$ increased risk of ALRI incidence. This finding is similar to the results of the last review of this literature, published 9 years ago, which estimated a $4-12 \%$ increase in ALRI for every $20-\mu \mathrm{g} / \mathrm{m}^{3}$ increase in daily $\mathrm{PM}_{2.5}$ exposure (Romieu et al. 2002).

The previous review encompassed a broader age range (children up to 15 years of age) and a wider range of health outcomes, including respiratory symptoms and both upper and lower respiratory infections (Romieu et al. 2002). Of the 42 studies reviewed, only three studies focused specifically on pneumonia, and only one of these studies was a panel study with the potential to assess effects of long-term effects (Pino et al. 1998). Only three studies were conducted in developing countries of Asia, the region where populations experience the highest exposures and the 
Table 4 ALRI risk per $10 \mu \mathrm{g} / \mathrm{m}^{3}$ $\mathrm{PM}_{2.5}$ : a comparison of approaches

\begin{tabular}{llll}
\hline & Beta (per unit $\left.\mathrm{PM}_{2.5}\right)$ & $\mathrm{SE}$ & Variation between cohort \\
\hline Individual study results & & & \\
Brauer et al. (2002) & 0.122565 & 0.305949 & \\
Hertz-Picciotto et al. (2007) & 0.104946 & 0.039808 & \\
Karr et al. (2007) & 0.086178 & 0.022883 & \\
Karr et al. (2009) & 0.039221 & 0.109909 & 0 \\
Model results & & & $9.99 \times 10^{-7}$ \\
Fixed effects model & 0.089 & 0.019 & $3.59 \times 10^{-3}$ \\
Random effects model & 0.089 & 0.019 & $\mathrm{NA}$ \\
Bayesian model & 0.117 & &
\end{tabular}

greatest burden of ALRI attributable to air pollution (Cohen et al. 2004; HEI International Scientific Oversight Committee 2004; Smith et al. 2004), and only three of the studies had data on $\mathrm{PM}_{2.5}$. There were no studies in some regions, such as Africa, with large burdens of disease due to ALRI and growing levels of urban air pollution.

This systematic review suggests that the situation has improved to some extent, with incremental evidence from more polluted regions. The results from additional shortterm studies suggest that the health effects of air pollution continue to be observed at higher concentrations and across a range of geographic locations. When the first estimates of the burden of disease from air pollution were made, mortality in children under 5 years of age was estimated based on a meta-analysis of five short-term (time series) studies of $\mathrm{PM}_{10}$ and daily mortality (Cohen et al. 2004). Based on the results of the meta-analysis, each $10-\mu \mathrm{g} / \mathrm{m}^{3}$ increase in ambient $\mathrm{PM}_{10}$ concentrations above 7.5 up to
$50 \mu \mathrm{g} / \mathrm{m}^{3}$ was associated with a $1 \%(95 \%$ confidence interval (CI) $0.9-3.1 \%$ ) increase in daily mortality from ARI in children aged $0-4$ years. The shape of the concentration-response function was assumed to be linear between 7.5 and $50 \mu \mathrm{g} / \mathrm{m}^{3}$, with city-specific $\mathrm{PM}_{2.5}$ concentrations not allowed to exceed $50 \mu \mathrm{g} / \mathrm{m}^{3}$ and the $\mathrm{PM}_{2.5} / \mathrm{PM}_{10}$ ratio assumed to be 0.5 .

Perhaps the most important recent addition to the literature, particularly with respect to estimating of the global burden of ALRI attributable to air pollution, are the cohort studies that relate ALRI occurrence to annual average $\mathrm{PM}_{2.5}$ concentrations. These studies provide estimates of effect on ALRI incidence, a metric preferable to mortality for estimating the global burden of ALRI due to air pollution. The cohort studies also differ from the majority of studies of PM and ALRI morbidity in that they provide estimates of effects in terms of $\mathrm{PM}_{2.5}$ rather than $\mathrm{PM}_{10} \cdot \mathrm{PM}_{2.5}$ is the most consistent and robust indicator of

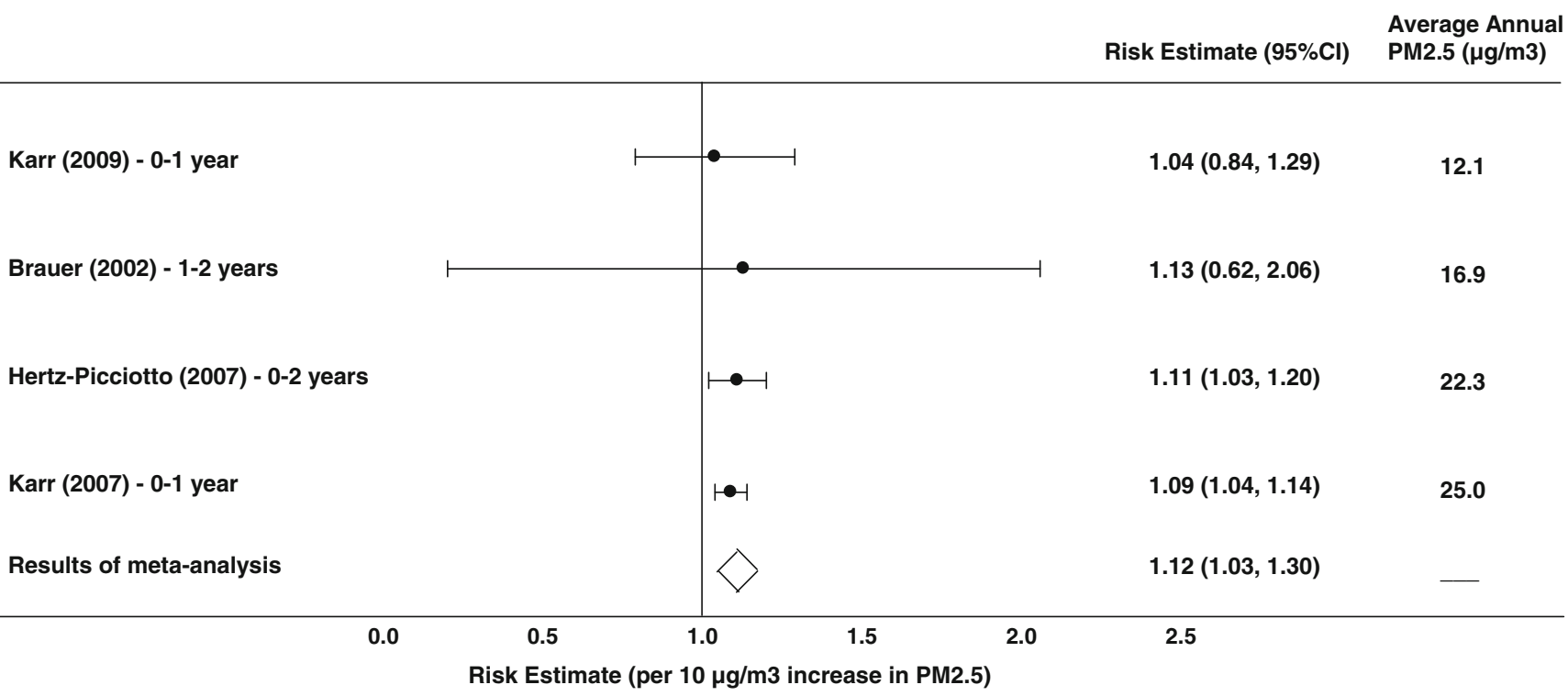

Fig. 2 Risk estimates from longer-term studies of $\mathrm{PM}_{2.5}$ and ALRI in children below 5 years of age, ordered by average annual $\mathrm{PM}_{2.5}$ concentration 


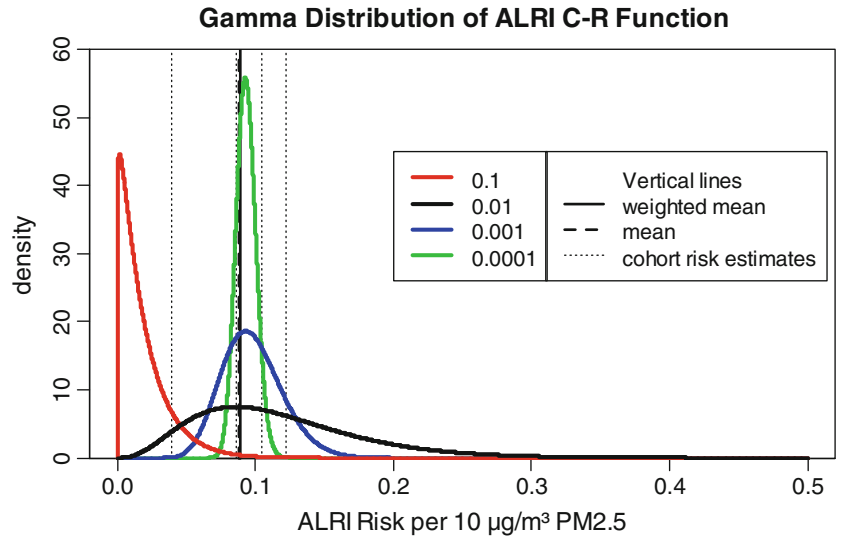

Fig. 3 Gamma distribution of ALRI risk per $10 \mu \mathrm{g} / \mathrm{m}^{3} \mathrm{PM}_{2.5}$

air pollution from combustion sources that can be estimated for all global regions (Cohen et al. 2004; van Donkelaar et al. 2010). These studies also quantify the excess risk of ALRI due to cumulated, longer-term exposure to $\mathrm{PM}_{2.5}$ and were therefore the focus of our quantitative meta-analysis.

Air pollution and respiratory mortality

Studies of outdoor air pollution and ALRI have focused on morbidity outcomes rather than mortality. Those studies which have focused on mortality have generally used the much broader "respiratory mortality" as an outcome. While the systematic search strategy employed here did not fully capture studies of air pollution and neonatal or child respiratory mortality, we know many studies of air pollution and respiratory mortality.

The available evidence does not demonstrate a consistent association between increased short-term exposure to $\mathrm{PM}_{10}$ and respiratory mortality (Fig. 4). Two of published studies showed a positive association between ALRI and $\mathrm{PM}_{10}$ (Conceicao et al. 2001; Ha et al. 2003). Ha et al. (2003) observed a 14\% greater risk of respiratory mortality in Korean infants with a relative risk of 1.14 [1.10, 1.19] for each interquartile increase in $\mathrm{PM}_{10}$ exposure $\left(42.9 \mu \mathrm{g} / \mathrm{m}^{3}\right)$. Conceicao et al. (2001) found a significant but smaller association between per unit increases in $\mathrm{PM}_{10}$ exposure and mortality in Brazilian children below age 5. A third study conducted in Brazil (Saldiva et al. 1994) found an increased association with $\mathrm{NO}_{2}$ exposure, but a negative, albeit insignificant relative risk of respiratory mortality from $\mathrm{PM}_{10}$ in children below age 5. Recent evidence on the effect of short-term exposures on respiratory mortality, particularly at higher concentrations, was kindly shared by investigators of the multi-city coordinated analysis of air pollution and mortality in Latin American cities (ESCALA). Although

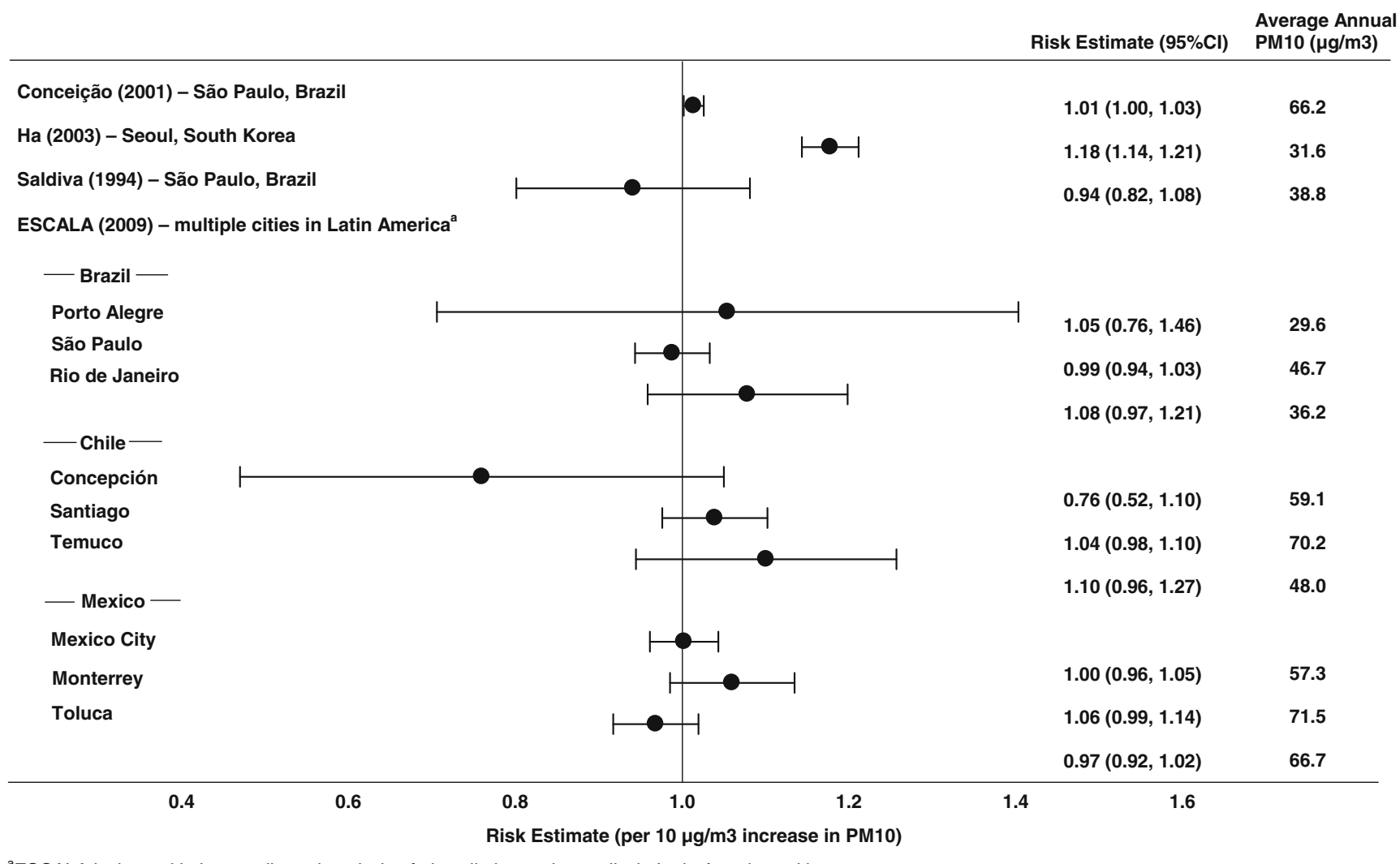

${ }^{a}$ ESCALA is the multi-city coordinated analysis of air pollution and mortality in Latin American cities

Fig. 4 Estimates from time series studies of $\mathrm{PM}_{10}$ and respiratory mortality in children under 5 years of age 
city-specific results for São Paolo, Brazil and Toluca, Mexico indicate a negative association between $\mathrm{PM}_{10}$ and mortality, most of the city-specific analyses were too small to reliably estimate effects on respiratory mortality in young children as evidenced by the wide confidence intervals.

Several studies provide estimates of longer-term exposure to particulate air pollution and mortality from respiratory causes (Ritz et al. 2006; Woodruff et al. 1997, 2006, 2008). These studies have been conducted in the USA, in areas with relatively low average PM concentrations (see Table 5).

Results in the context of evidence from other combustion source pollution

The capacity for combustion-derived air pollution to affect resistance to infection is well-documented (Thomas and Zelikoff 1999). More recent studies suggest a role for fine particles $\left(\mathrm{PM}_{2.5}\right.$; Zelikoff et al. 2003). Effects on airway resistance, epithelial permeability, and macrophage function have been associated with various components of the complex mixture of air pollution generated by indoor and outdoor sources. There has also been considerable recent interest in the role of particle-associated transition metals, such as iron, in producing oxidative stress in the lung (Ghio
2004; Ghio and Cohen 2005), which has been hypothesized to be a common factor in a range of adverse effects of air pollution on the cardiovascular and respiratory systems (Kelly 2003). PM-associated transition metals have also been associated with altered host defenses in rats (Zelikoff et al. 2002).

Consistent with the evidence from toxicological studies, recent reviews of the epidemiologic literature on ALRI in young children and exposure to combustion source pollution, including air pollution from outdoor and indoor sources, as well as secondhand smoke, demonstrate a consistent association between ALRI and air pollution exposure. Exposure to air pollution from indoor combustion of solid fuels has also been consistently associated with increased incidence and mortality risk in 14 studies in developing countries (Smith et al. 2004). A recent metaanalysis by Dherani and colleagues found that young children exposed to household air pollution from unprocessed household solid fuel use had a 1.8 (95\% CI 1.5-2.2) fold greater risk of pneumonia compared to unexposed children (Dherani et al. 2008). The definition of ALRI varies among the different studies, with studies relying on maternal recall most likely to have lower specificity and possibly poorer validity. Sensitivity analyses, however, did not identify any substantial effects resulting from differ-

Table 5 Associations between particulate matter and postneonatal respiratory mortality

\begin{tabular}{|c|c|c|c|}
\hline & Study population & Pollutant $\left(\mu \mathrm{g} / \mathrm{m}^{3}\right)$ & Odds ratio \\
\hline \multirow[t]{8}{*}{ Woodruff et al. 1997} & \multirow[t]{4}{*}{ US non-low birth weight infants } & Low $\mathrm{PM}_{10}, 11.90-28.00$ & Reference \\
\hline & & Medium $\mathrm{PM}_{10}, 28.01-40.0$ & $1.08(0.87,1.33)$ \\
\hline & & High $\mathrm{PM}_{10}, 40.01-68.80$ & $1.40(1.05,1.85)$ \\
\hline & & Continuous $\mathrm{PM}_{10}$ & $1.20(1.06,1.36)$ \\
\hline & \multirow[t]{4}{*}{ US low birth weight infants } & Low $\mathrm{PM}_{10}, 11.90-28.00$ & Reference \\
\hline & & Medium $\mathrm{PM}_{10}, 28.01-40.0$ & $0.93(0.73,1.18)$ \\
\hline & & High $\mathrm{PM}_{10}, 40.01-68.80$ & $1.18(0.86,1.61)$ \\
\hline & & Continuous $\mathrm{PM}_{10}$ & $1.05(0.91,1.22)$ \\
\hline \multirow[t]{3}{*}{ Ritz et al. 2006} & \multirow[t]{3}{*}{ California infants $7-12$ months of age } & Low $\mathrm{PM}_{10},<37.6 \mu \mathrm{g} / \mathrm{m}^{3}$ & Reference \\
\hline & & Medium $\mathrm{PM}_{10}, 37.6$ to $<52.6 \mu \mathrm{g} / \mathrm{m}^{3}$ & $1.55(0.88,2.73)^{\mathrm{a}}$ \\
\hline & & High $\mathrm{PM}_{10}, \geq 52.6 \mu \mathrm{g} / \mathrm{m}^{3}$ & $2.42(1.15,5.10)^{\mathrm{a}}$ \\
\hline \multirow[t]{2}{*}{ Woodruff et al. 2006} & \multirow[t]{2}{*}{ California infants } & \multirow[t]{2}{*}{ Per $10 \mu \mathrm{g} / \mathrm{m}^{3}$ increase in $\mathrm{PM}_{2.5}$} & $2.15(1.15,4.02)$ \\
\hline & & & $2.13(1.12,4.05)^{\mathrm{b}}$ \\
\hline \multirow[t]{4}{*}{ Woodruff et al. 2008} & \multirow[t]{4}{*}{ US infants } & \multirow[t]{2}{*}{ Per IQR increase $\left(11 \mu \mathrm{g} / \mathrm{m}^{3}\right)$ in $\mathrm{PM}_{10}$} & $1.18(1.06,1.31)^{\mathrm{c}}$ \\
\hline & & & $1.16(1.06,1.27)^{\mathrm{d}}$ \\
\hline & & \multirow[t]{2}{*}{ Per IQR increase $\left(7 \mu \mathrm{g} / \mathrm{m}^{3}\right)$ in $\mathrm{PM}_{2.5}$} & $1.11(0.96,1.29)^{\mathrm{c}}$ \\
\hline & & & $1.05(0.87,1.23)^{\mathrm{d}}$ \\
\hline
\end{tabular}

Sources: Ritz et al. (2006), Woodruff et al. (1997), Woodruff et al. (2006), and Woodruff et al. (2008)

${ }^{a}$ Adjusted for infant gender, level of prenatal care, maternal factors, season, region, $\mathrm{CO}, \mathrm{NO}_{2}$, and $\mathrm{O}_{3}$

${ }^{\mathrm{b}}$ Adjusted for maternal race, education, age, maternal status, and parity

${ }^{\mathrm{c}}$ Adjusted for maternal factors, percentage below poverty, region, birth month, and birth year

${ }^{\mathrm{d}}$ Adjusted for maternal factors, percentage below poverty, region, birth month, year, $\mathrm{CO}, \mathrm{O}_{3}$, and $\mathrm{SO}_{2}$ 
ences in outcome assessment or other aspects of study design, thus strengthening the credibility of the summary estimate reported. While two recent studies have attempted to measure levels of air pollution (Ezzati 2005; Ezzati and Kammen 2001), the vast majority of studies rely on qualitative indicators of household air pollution.

Children's exposure to SHS, defined as having one or both parents who smoke indoors, has also been associated with increased incidence of ALRI infections and hospital admissions (U.S. Department of Health and Human Services 2006). Similar to the studies on ambient air pollution and ALRI, the vast majority of studies in the SHS evidence base used clinical definitions of illness; only a small proportion actually had data on confirmed RSV infections (U.S. Department of Health and Human Services 2006). Increased risks are greatest for maternal smoking, with evidence suggesting that exposure may increase the likelihood of infection or make infections more severe (U. S. Department of Health and Human Services 2006). Higher risks are observed for younger children, with children aged 3-6 years estimated to have about one third the risk of children aged 0-2 years ( $\mathrm{Li}$ et al. 1999), with recent estimates suggesting that around 165,000 children under five die from LRI caused by exposure to secondhand smoke each year (Öberg et al. 2011).

It is difficult to estimate the independent effects of exposure to ambient PM from different combustion sources, particularly when one source dominates total exposure. Nonetheless, the evidence indicates that adverse effects of exposure to outdoor air pollution can be estimated even in populations where total exposure to combustionderived PM is dominated by PM from other sources, including smoking and household air pollution from cooking with solid fuels. For example, in an analysis of long-term exposure to $\mathrm{PM}_{2.5}$ pollution and mortality in the American Cancer Society cohort, which includes smokers and nonsmokers, the effects of air pollution on all-cause, cardiopulmonary, and lung cancer mortality remained after adjustment for smoking status (Pope et al. 2002). In stratified analyses of the same cohort, while the strongest risks were observed in never-smokers, former and current smokers also experienced increased risks of cardiopulmonary and lung cancer mortality (Pope et al. 2002). Similarly, analyses of long-term exposure to air pollution and cardiovascular disease incidence in women found consistent, strong associations between $\mathrm{PM}_{2.5}$ exposure and cardiovascular events after controlling for smoking and after stratifying by smoking status (Miller et al. 2007). In addition, a recent systematic review of the epidemiology on air pollution and health in rapidly developing countries of Asia found that the prevalence of respiratory symptoms in adults and children remained associated with residence in more polluted Chinese cities after controlling for tobacco smoke exposure and household air pollution from solid fuel use (HEI International Scientific Oversight Committee 2010).

\section{Implications for estimating global burden of disease}

Although most studies, both of short- and longer-term exposure, have been conducted in places where ALRI does not account for a substantial burden of disease, the major determinant of the burden ALRI mortality across global regions is not incidence, but rather differences in case fatality rates (CFR). For example, only $1-3 \%$ of child mortality is due to ALRI in the countries where the longer-term studies reviewed here were conducted compared to at least $15 \%$ of deaths in much of South Asia, Sub-Saharan Africa, and Latin America (World Health Organization 2010). These are also areas where household air pollution from cooking and heating with solid fuels is not an issue. Thus, the generalizability of these results to areas with higher concentrations, and different patterns of disease must be considered when conducting health impact assessments.

Regional differences in CFR are strongly driven by susceptibility (young children in less developed regions are much more likely to be malnourished or immunocompromised, for example) and timely access to adequate treatment. Although ALRI incidence is higher, it is not evident that developing countries have higher incidence of ALRI of bacterial origin, or lower incidence of viral infection; estimates of RSV-associated ALRI are highly variable by country and region, for example (Nair et al. 2010). Moreover, as the evidence base uses clinical criteria for diagnosing ALRI, at present we are unable to determine whether air pollution may increase the severity of and/or possibly susceptibility to ALRI differently depending on whether the illness is viral or bacterial in origin. Thus, the extrapolation of estimates for mortality based on developed country research is likely to be problematic, since these countries will have low case fatality rates.

There are striking differences in the public health implications of air pollution for regions that vary widely in population size and per capita incidence of ALRI. For example, while the USA has twice as many children under five as Mexico (United States Census Bureau 2011), due to differences in national estimates of ALRI incidence $(0.026$ and 0.29 cases per child per year in the USA and Mexico, respectively (Rudan et al. 2004)), a $10-\mu \mathrm{g} / \mathrm{m}^{3}$ increase in $\mathrm{PM}_{2.5}$ exposure would result in nearly 66,000 additional ALRI cases in the USA but nearly 372,000 additional cases in Mexico. Similarly, Mexico and India are estimated to have the same rate of ALRI incidence (Rudan et al. 2004), but with India's much larger population of young 
children (United States Census Bureau 2011), a similar $10-\mu \mathrm{g} / \mathrm{m}^{3}$ increase in $\mathrm{PM}_{2.5}$ exposure would result in over four million new cases of ALRI. Although these calculations assume a linear concentration-response function over the range of concentrations experienced in these countries, the public health implications of increased exposure to particulate pollution would still likely be much greater in countries with large populations of young children and high incidence of ALRI even if the slope of the concentration-response function decreased at higher concentrations.

The cohort studies reviewed here were conducted in developed countries with relatively low levels of air pollution; the highest average $\mathrm{PM}_{2.5}$ concentration reported in these studies is $25 \mu \mathrm{g} / \mathrm{m}^{3}$, while concentrations in less developed countries can be several times greater (Sivertsen 2006; van Donkelaar et al. 2010). Estimating the global burden of ALRI due to fine particulate air pollution will require developing a concentration-response function across this broad range of ambient concentrations. In the absence of direct evidence on the effects exposure to higher levels of outdoor $\mathrm{PM}_{2.5}$, this function should be informed by evidence on ALRI risk associated with exposure to $\mathrm{PM}_{2.5}$ from other combustion sources, such as SHS and household solid fuel use. Recent work by Pope et al. (2009) on cardiovascular mortality suggests a general approach (Pope et al. 2009), and new results from a randomized trial of ALRI risk due to indoor burning of solid fuels may provide the required estimates for household air pollution (Bruce et al. 2007).

Acknowledgments The systematic review in this work was partially supported by a grant for Child Health Epidemiology Reference Group to the US Fund for UNICEF and for the Global Burden of Diseases, Injuries, and Risk Factors Study. Both grants were from the Bill \& Melinda Gates Foundation. The sponsors of the study had no role in study design, data collection, data analysis, data interpretation, writing of the report, or decision to submit manuscript. We are grateful to our colleagues in the expert working group on ambient air pollution in the Global Burden of Diseases, Injuries, and Risk Factors Study 2010; to Victor Miranda for extracting the results from the ESCALA study; to Nigel Bruce and John Balmes for their insight on global patterns in ALRI incidence; and to Morgan Younkin for his administrative assistance.

Disclaimer The views expressed in this paper are those of the authors and do not necessarily reflect the views of the Health Effects Institute or its sponsors.

Conflict of interest The authors declare that they have no conflict of interest.

Open Access This article is distributed under the terms of the Creative Commons Attribution Noncommercial License which permits any noncommercial use, distribution, and reproduction in any medium, provided the original author(s) and source are credited.

\section{Appendix}

Bayesian approach for meta-analysis

We present an approach to summarize the uncertainty in the association between exposure to $\mathrm{PM}_{2.5}$ and the incidence of ALRI using a two-stage Bayesian hierarchical model. We assume that the true but unknown risks are positive and exchangeable among the cohort studies. We develop a strategy to select the prior distributions on the unknown parameters of risk distribution when we have available a limited number of studies.

Let $P$ be the proportion of children with ALRI in the population. The association between exposure to $\mathrm{PM}_{2.5}$ and the incidence of ALRI is given by the logistic regression equation

$\log \left(\frac{P}{1-P}\right)=\beta \mathrm{PM}_{2.5}+\gamma Z$,

where $\beta$ is the log-odds ratio for $\mathrm{PM}_{2.5}$ and $\gamma$ is a vector of unknown parameters relating potentially confounding risk factors $Z$ to the log-odds of ALRI.

We assume that $\beta=\left(\beta_{1}, \ldots, \beta_{K}\right)$, representing the ALRI risks for the $K$ cohort studies, are exchangeable. In other words, our prior belief about $\beta_{i}$ and $\beta_{j}$ are identical. We construct an exchangeable prior by assuming that $\beta$ is a random sample from a distribution. The reported cohort risk estimate $\left(\widehat{\beta}_{k}\right)$ are then assumed to vary about the true risk $\left(\beta_{k}\right)$ in Eq. 2, and the individual $\beta_{k}$ are assumed to be random variables from a distribution conditional on additional parameters called hyperparameters in Eq. 3. The $\beta_{k}$ is assumed to have a Gamma distribution specified by shape and scale parameters. The gamma distribution is selected for the true risk since we believe that the association between the adverse health event (ALRI) and $\mathrm{PM}_{2.5}$ is positive. The gamma distribution also can characterize variation in risk among studies in a nonsymmetric manner, a pattern often observed. The $\beta_{k}$ has population mean $\left(\mu_{\beta}\right)$ and between study variation $\left(\sigma_{\beta}^{2}\right)$.

We assume for the $k$ th cohort study:

$\widehat{\beta}_{k} \mid \beta_{k} \sim N\left(\beta_{k}, \widehat{v}_{k}^{2}\right)$ for $k=1, \ldots, K$,

where $\widehat{\beta}_{k}$ is the reported risk estimates, $\beta_{k}$ is the unknown true risk, and $\widehat{v}_{k}^{2}$ is the known sampling variance of $\widehat{\beta}_{k}$ conditional on $\beta_{k}$, var $\left.\widehat{\beta_{k}} \mid \beta_{k}\right)$, of the $k$ th cohort.

At the first stage, the true risks, $\beta_{1}, \ldots, \beta_{k}$, are assumed to be a random sample from a gamma distribution with shape and scale parameters, $\alpha>0$ and $\theta>0$, respectively:

$\beta_{k} \mid \alpha, \theta \sim G(\alpha, \theta)$ for any $k$. 
Table 6 ALRI risk estimates reported by four cohort studies (per $10 \mu \mathrm{g} / \mathrm{m}^{3} \mathrm{PM}_{2.5}$ )

\begin{tabular}{llll}
\hline Index & Citation & $\widehat{\beta}_{k}$ & $\widehat{v}_{k}$ \\
\hline 1 & Brauer et al. (2002) & 0.122565 & 0.305949 \\
2 & Hertz-Picciotto et al. (2007) & 0.104946 & 0.039808 \\
3 & Karr et al. (2007) & 0.086178 & 0.022883 \\
4 & Karr et al. (2009) & 0.039221 & 0.109909 \\
\hline
\end{tabular}

The mean $\left(\mu_{\beta}\right)$ and variance $\left(\sigma_{\beta}^{2}\right)$ of $G(\alpha, \theta)$ are $\alpha \theta$ and $\alpha \theta^{2}$, respectively. We reparameterize them by changing the shape and scale parameters to $\mu_{\beta}$ and $\sigma_{\beta}^{2}$ for convenience as follows:

$\beta_{k} \mid \mu_{\beta}, \sigma_{\beta}^{2} \sim G\left(\mu_{\beta}^{2} / \sigma_{\beta}^{2}, \sigma_{\beta}^{2} / \mu_{\beta}\right)$.

At the second stage, the hyperparameters $\mu_{\beta}$ and $\sigma_{\beta}^{2}$ are assumed independent. We apply non-informative prior distributions for both $\mu_{\beta}$ and $\sigma_{\beta}^{2}$ using the uniform distribution and diffuse the prior distributions by taking large values of the uniform distribution. Thus, we have

$\mu_{\beta} \sim U\left(0, I_{\mu}\right)$ and $\sigma_{\beta}^{2} \sim U\left(0, I_{\sigma^{2}}\right)$.

To estimate the unknown parameters, we ran three sequences (chains) of the Gibbs sampler using different initial values, each chain for 11,000 iterations and removed the first 1,000 samples. We assessed convergence through the use of trace plots. All estimates were obtained by WinBUGS (version 1.4.3, http://www.mrc-bsu.cam.ac.uk/bugs/).

Values for $\widehat{\beta}_{k}$ and $\widehat{v}_{k}$ for the four ALRI cohort studies identified to be appropriate to estimate risk are given in Table 6.

We first applied the random effects model as a conventional approach but found no power to detect between-cohort variation due to the small number (here 4) of cohort available. The pooled risk estimate was 0.089 with standard error 0.019 , and the variance estimate (between-cohort variation) was $9.99 \times 10^{-7}$. This very small variance indicates no difference between the cohort risks, and therefore, the pooled risk estimate from the random effects model is almost the same as the inverse-variance weighted mean.

We then considered the range of reported cohort risk estimates and the observed variance between the $\widehat{\beta}_{k}$ as guidance in selecting values for $I_{\mu}$ and $I_{\sigma^{2}}$, respectively, to implement the Bayesian approach. We present the medians of the posterior distribution of $\alpha$ and $\theta$ and the mean and variance of $G(\alpha, \theta)$ for selected values of $I_{\mu}$ and $I_{\sigma^{2}}$ in Table 7 .

The medians of the posterior distribution of the shape and scale parameters, $\alpha$ and $\theta$, are insensitive to the specification of $I_{\mu}$ but sensitive to that of $I_{\sigma^{2}}$. In Fig. 3, $G(\alpha, \theta)$ is plotted for the values of $I_{\sigma^{2}}$ presented in Table 7 with $I_{\mu}=1,000$. The variance $G(\alpha, \theta)$ increases as $I_{\sigma^{2}}$ increases as expected since we have only four risk estimates available to inform us on the estimate of $G(\alpha, \theta)$. Thus, the specification of the prior distribution of $\sigma_{\beta}^{2}$ is highly influential.

We select $I_{\sigma^{2}}=10^{-2}$ since it is only slightly larger than the observed variance of the $\widehat{\beta}_{k}, 1.3 \times 10^{3}$. We are selecting a moderately diffuse prior for $\sigma_{\beta}^{2}$ compared to variation in limited observed data.

Thus, our best estimate for the posterior medians of the shape and scale parameters of the gamma distribution is 3.766 and 0.031 . This gamma distribution covers the mean (0.088), inverse-variance weighted mean (0.089), and four cohort estimates all (Fig. 3). For the estimated gamma distribution, $G(3.766,0.031)$, the mean is 0.117 with a $95 \%$ range of $(0.030,0.261)$ and the variance is $3.63 \times 10^{-3}$, which is much larger than the variance estimate from the random effects model. By diffusing the priors, the Bayesian model estimated both larger mean ALRI risk and variation in risk among the cohort studies (Table 4). Taking exponential of the risk, we obtain the odds ratio 1.12 $(1.03,1.30)$ per $10 \mathrm{PM}_{2.5}$.

Table 7 Estimated gamma distributions

\begin{tabular}{llclccc}
\hline$I_{\mu}$ & $I_{\sigma^{2}}$ & $\alpha^{\text {a }}$ (posterior median) & $\theta^{\mathrm{b}}$ (posterior median) & Mean of $G(\alpha, \theta)$ & Variance of $G(\alpha, \theta)$ & $\begin{array}{l}95 \% \text { range of } G(\alpha, \theta) \\
(2.5 \text { th and } 97.5 \text { th percentiles) }\end{array}$ \\
\hline 10 & $10^{-1}$ & 1.084 & 0.175 & 0.189 & $3.30 \times 10^{-2}$ & $0.0061,0.6761$ \\
1,000 & $10^{-1}$ & 1.084 & 0.175 & 0.189 & $3.30 \times 10^{-2}$ & $0.0061,0.6761$ \\
10 & $10^{-2}$ & 3.766 & 0.031 & 0.117 & $3.63 \times 10^{-3}$ & $0.0302,0.2611$ \\
1,000 & $10^{-2}$ & 3.766 & 0.031 & 0.117 & $3.63 \times 10^{-3}$ & $0.0302,0.2611$ \\
10 & $10^{-3}$ & 19.77 & $4.94 \times 10^{-3}$ & 0.098 & $4.82 \times 10^{-4}$ & $0.0594,0.1451$ \\
1,000 & $10^{-3}$ & 19.93 & $4.90 \times 10^{-3}$ & 0.098 & $4.79 \times 10^{-4}$ & $0.0600,0.1460$ \\
10 & $10^{-4}$ & 169.4 & $5.53 \times 10^{-4}$ & 0.094 & $5.17 \times 10^{-5}$ & $0.0797,0.1077$ \\
1,000 & $10^{-4}$ & 169.4 & $5.53 \times 10^{-4}$ & 0.094 & $5.17 \times 10^{-5}$ & $0.0797,0.1077$ \\
\hline
\end{tabular}

${ }^{\mathrm{a}} \alpha$ is the shape parameter of the gamma distribution in Eq. 3

${ }^{\mathrm{b}} \theta$ is the scale parameter of the gamma distribution in Eq. 3 


\section{References}

Barnett AG, Williams GM, Schwartz J, Neller AH, Best TL, Petroeschevsky AL, Simpson RW (2005) Air pollution and child respiratory health - a case-crossover study in Australia and new Zealand. Am J Respir Crit Care Med 171(11):1272-1278. doi:10.1164/rccm.200411-1586OC

Braga AL, Saldiva PH, Pereira LA, Menezes JJ, Conceicao GM, Lin CA, Zanobetti A, Schwartz J, Dockery DW (2001) Health effects of air pollution exposure on children and adolescents in Sao Paulo, Brazil. Pediatr Pulmonol 31(2):106-113. doi:10.1002/ 1099-0496(200102)31:2<106::AID-PPUL1017>3.0.CO;2-M

Brauer M, Hoek G, Van Vliet P, Meliefste K, Fischer PH, Wijga A, Koopman LP, Neijens HJ, Gerritsen J, Kerkhof M, Heinrich J, Bellander T, Brunekreef B (2002) Air pollution from traffic and the development of respiratory infections and asthmatic and allergic symptoms in children. Am J Respir Crit Care Med 166 (8): 1092-1098

Bruce N, Weber M, Arana B, Diaz A, Jenny A, Thompson L, McCracken J, Dherani M, Juarez D, Ordonez S, Klein R, Smith KR (2007) Pneumonia case-finding in the RESPIRE Guatemala indoor air pollution trial: standardizing methods for resourcepoor settings. Bull World Health Organ 85(7):535-544

Cohen AJ, Anderson HR, Ostro B, Pandey KD, Krzyzanowski M, Künzli N, Gutschmidt K, Pope CAI, Romieu I, Samet JM, Smith KR (2004) Urban air pollution. In: LA Ezzati M, Rodgers A, Murray CJL (eds) Comparative quantification of health risks: global and regional burden of disease attributable to selected major risk factors, vol 2. World Health Organization, Geneva, pp $1153-1433$

Collaborative Working Group (CWG) on Air Pollution Poverty and Health in HCMC (2011) The effects of short-term exposure on hospital admissions for acute lower respiratory infections in young children of Ho Chi Minh City. Health Effects Institute, Boston

Conceicao GM, Miraglia SG, Kishi HS, Saldiva PH, Singer JM (2001) Air pollution and child mortality: a time-series study in Sao Paulo, Brazil. Environ Health Perspect 109(Suppl 3):347-350

Deb SK (1998) Acute respiratory disease survey in Tripura in case of children below five years of age. J Indian Med Assoc 96(4):111-116

Dherani M, Pope D, Mascarenhas M, Smith KR, Weber M, Bruce N (2008) Indoor air pollution from unprocessed solid fuel use and pneumonia risk in children aged under five years: a systematic review and meta-analysis. Bull WHO 86(5):390-398. doi:10.2471/blt.07.044529

Ezzati M (2005) Indoor air pollution and health in developing countries. Lancet 366(9480):104-106

Ezzati M, Kammen DM (2001) Quantifying the effects of exposure to indoor air pollution from biomass combustion on acute respiratory infections in developing countries. Environ Health Perspect 109(5):481-488

Ghio AJ (2004) Biological effects of Utah Valley ambient air particles in humans: a review. Journal of Aerosol Medicine-Deposition Clearance and Effects in the Lung 17(2):157-164

Ghio AJ, Cohen MD (2005) Disruption of iron homeostasis as a mechanism of biologic effect by ambient air pollution particles. Inhal Toxicol 17(13):709-716. doi:10.1080/08958370500224482

Gouveia N, Fletcher T (2000) Respiratory diseases in children and outdoor air pollution in Sao Paulo, Brazil: a time series analysis. Occup Environ Med 57(7):477-483

Ha EH, Lee JT, Kim H, Hong YC, Lee BE, Park HS, Christiani DC (2003) Infant susceptibility of mortality to air pollution in Seoul, South Korea. Pediatrics 111(2):284-290

HEI International Scientific Oversight Committee (2004) Health effects of outdoor air pollution in developing countries of Asia: a literature review. Special report 15. Health Effects Institute, Boston

HEI International Scientific Oversight Committee (2010) Outdoor air pollution and health in the developing countries of Asia: a comprehensive review. Special report 18. Health Effects Institute, Boston

Hernandez-Cadena L, Barraza-Villarreal A, Ramirez-Aguilar M, Moreno-Macias H, Miller P, Carbajal-Arroyo LA, Romieu I (2007) Infant morbidity caused by respiratory diseases and its relation with the air pollution in Juarez City, Chihuahua, Mexico. Salud Publica Mex 49(1):27-36

Hertz-Picciotto I, Baker RJ, Yaw PS, Dostal M, Joad JP, Lipsett M, Greenfield T, Herr CEW, Benes I, Shumway RH, Pinkerton KE, Sram R (2007) Early childhood lower respiratory illness and air pollution. Environ Health Perspect 115:1510-1526. doi:10.1289/ ehp. 9617

Karr C, Lumley T, Shepherd K, Davis R, Larson T, Ritz B, Kaufman J (2006) A case-crossover study of wintertime ambient air pollution and infant bronchiolitis. Environ Health Perspect 114 (2):277-281. doi:10.1289/ehp.8313

Karr C, Lumley T, Schreuder A, Davis R, Larson T, Ritz B, Kaufman J (2007) Effects of subchronic and chronic exposure to ambient air pollutants on infant bronchiolitis. Am J Epidemiol 165 (5):553-560. doi:10.1093/aje/kwk032

Karr CJ, Rudra CB, Miller KA, Gould TR, Larson T, Sathyanarayana S, Koenig JQ (2009) Infant exposure to fine particulate matter and traffic and risk of hospitalization for RSV bronchiolitis in a region with lower ambient air pollution. Environ Res 109 (3):321-327. doi:10.1016/j.envres.2008.11.006

Kelly FJ (2003) Oxidative stress: its role in air pollution and adverse health effects. Occup Environ Med 60(8):612-616

Li JSM, Peat JK, Xuan W, Berry G (1999) Meta-analysis on the association between environmental tobacco smoke (ETS) exposure and the prevalence of lower respiratory tract infection in early childhood. Pediatr Pulmonol 27(1):5-13. doi:10.1002/(sici) 1099-0496(199901)27:1<5::aid-ppul3>3.0.co;2-5

Miller KA, Siscovick DS, Sheppard L, Shepherd K, Sullivan JH, Anderson GL, Kaufman JD (2007) Long-term exposure to air pollution and incidence of cardiovascular events in women. $\mathrm{N}$ Engl J Med 356(5):447-458. doi:10.1056/NEJMoa054409

Muhling P, Bory J, Haupt H (1984) Effect of air pollution on respiratory tract diseases in small children. Morbidity rate in residential areas with varying degrees of severe pollution. Fortschr Med 102(34):831-834

Nair H, Nokes DJ, Gessner BD, Dherani M, Madhi SA, Singleton RJ, O'Brien KL, Roca A, Wright PF, Bruce N, Chandran A, Theodoratou E, Sutanto A, Sedyaningsih ER, Ngama M, Munywoki PK, Kartasasmita C, Simões EAF, Rudan I, Weber MW, Campbell H (2010) Global burden of acute lower respiratory infections due to respiratory syncytial virus in young children: a systematic review and meta-analysis. Lancet 375 (9725):1545-1555

Öberg M, Jaakkola MS, Woodward A, Peruga A, Prüss-Ustün A (2011) Worldwide burden of disease from exposure to secondhand smoke: a retrospective analysis of data from 192 countries. The Lancet 377(9760):139-146. doi:10.1016/S0140-6736(10) 61388-8

Ostro BD, Eskeland GS, Sanchez JM, Feyzioglu T (1999) Air pollution and health effects: a study of medical visits among children in Santiago, Chile. Environ Health Perspect 107(1):69-73

Pino P RI, Villegas R, Walter T, Oyarzun M (1998) Wheezing bronchitis in infants: influence of airborne fine particulate matter and environmental tobacco smoke exposure. Am J Respir Crit Care Med A877.Abstract

Pope CA, Burnett RT, Thun MJ, Calle EE, Krewski D, Ito K, Thurston GD (2002) Lung cancer, cardiopulmonary mortality, 
and long-term exposure to fine particulate air pollution. JAMA, J Am Med Assoc 287(9):1132-1141

Pope CA 3rd, Burnett RT, Krewski D, Jerrett M, Shi Y, Calle EE, Thun MJ (2009) Cardiovascular mortality and exposure to airborne fine particulate matter and cigarette smoke: shape of the exposure-response relationship. Circulation 120(11):941948. doi:10.1161/CIRCULATIONAHA.109.857888

Pouliou T, Kanaroglou PS, Elliott SJ, Pengelly LD (2008) Assessing the health impacts of air pollution: a re-analysis of the Hamilton children's cohort data using a spatial analytic approach. Int J Environ Health Res 18(1):17-35. doi:10.1080/09603120701844290

Ritz B, Wilhelm M, Zhao Y (2006) Air pollution and infant death in southern California, 1989-2000. Pediatrics 118(2):493-502. doi:10.1542/peds.2006-0027

Romieu I, Samet JM, Smith KR, Bruce N (2002) Outdoor air pollution and acute respiratory infections among children in developing countries. J Occup Environ Med 44(7):640-649. doi:10.1097/01.jom.0000023383.41727.32

Rudan I, Tomaskovic L, Boschi-Pinto C, Campbell H (2004) Global estimate of the incidence of clinical pneumonia among children under five years of age. Bull World Health Organ 82(12):895-903

Saldiva PHN, Lichtenfels A, Paiva PSO, Barone IA, Martins MA, Massad E, Pereira JCR, Xavier VP, Singer JM, Bohm GM (1994) Association between air-pollution and mortality due to respiratorydiseases in children in Sao-Paulo, Brazil-a preliminary-report. Environ Res 65(2):218-225

Samet JM, Brauer M, Schlesinger R (2006) Particulate matter. In: Air quality guidelines: global update 2005. World Health Organization Regional Office for Europe, Copenhagen

Segala C, Poizeau D, Mesbah M, Willems S, Maidenberg M (2008) Winter air pollution and infant bronchiolitis in Paris. Environ Res 106(1):96-100. doi:10.1016/j.envres.2007.05.003

Sivertsen B (2006) Global ambient air pollution concentrations and trends. In: Air quality guidelines: Global update 2005. Particulate matter, ozone, nitrogen dioxide and sulfur dioxide. World Health Organization, Copenhagen, pp 31-59

Smith KR, Mehta S, M-F M (2004) Indoor air pollution from household use of solid fuels. In: LA Ezzati M, Rogers A, Murray CJL (eds) Global and regional burden of disease attributable to selected major risk factors, vol 2. World Health Organization, Geneva

Thomas P, Zelikoff J (1999) Air pollutants: modulators of pulmonary host resistance against infection. In: Holgate ST, Samet JM, Koren HS, Maynard RL (eds) Air pollution and health. Academic, San Diego
U.S. Department of Health and Human Services (2006) The health consequences of involuntary exposure to tobacco smoke: a report of the surgeon general. U.S. Department of Health and Human Services, Centers for Disease Control and Prevention, Coordinating Center for Health Promotion, National Center for Chronic Disease Prevention and Health Promotion, Office on Smoking and Health, Atlanta

United States Census Bureau (2011) International Data Base (IDB). United States Census Bureau. http://www.census.gov/ipc/www/ idb/index.php. Accessed 10 Jan 2011

van Donkelaar A, Martin RV, Brauer M, Kahn R, Levy R, Verduzco C, Villeneuve PJ (2010) Global estimates of ambient fine particulate matter concentrations from satellite-based aerosol optical depth: development and application. Environ Health Perspect 118(6):847-855

Williams BG, Gouws E, Boschi-Pinto C, Bryce J, Dye C (2002) Estimates of world-wide distribution of child deaths from acute respiratory infections. Lancet 2:25-32

Woodruff TJ, Grillo J, Schoendorf KC (1997) The relationship between selected causes of postneonatal infant mortality and particulate air pollution in the United States. Environ Health Perspect 105(6):608-612

Woodruff TJ, Parker JD, Schoendorf KC (2006) Fine particulate matter (PM2.5) air pollution and selected causes of postneonatal infant mortality in California. Environ Health Perspect 114 (5):786-790. doi:10.1289/ehp.8484

Woodruff TJ, Darrow LA, Parker JD (2008) Air pollution and postneonatal infant mortality in the United States, 1999-2002. Environ Health Perspect 116(1):110-115. doi:10.1289/ehp.10370

World Health Organization (2010) Health statistics and health information systems World Health Organization. http://www.who.int/healthinfo/ global_burden disease/en/index.html. Accessed 23 Dec 2010

Zanobetti A, Schwartz J, Gold D (2000) Are there sensitive subgroups for the effects of airborne particles? Environmental Health Perspectives 108(9):841-845

Zelikoff JT, Schermerhorn KR, Fang KJ, Cohen MD, Schlesinger RB (2002) A role for associated transition metals in the immunotoxicity of inhaled ambient particulate matter. Environmental Health Perspectives 110:871-875

Zelikoff JT, Chen LC, Cohen MD, Fang KJ, Gordon T, Li Y, Nadziejko C, Schlesinger RB (2003) Effects of inhaled ambient particulate matter on pulmonary antimicrobial immune defense. Inhal Toxicol 15(2):131-150. doi:10.1080/08958370390168201 